\title{
Ordu İli Arazi Örtüsü/Alan Kullanımı Değişiminin (1990-2018) CORINE Verileri Kullanılarak Değerlendirilmesi
}

\author{
Pervin YEŞiL' ${ }^{1}$, Mesut GÜZEL ${ }^{* 1}$ \\ ${ }^{1}$ Ordu Üniversitesi, Ziraat Fakültesi, Peyzaj Mimarlığı Bölümü, 52200, Ordu, Türkiye
}

(Alınış / Received: 13.10.2020, Kabul / Accepted: 12.07.2021, Online Yayınlanma / Published Online: 25.12.2021)

\section{Anahtar Kelimeler}

Peyzaj metrikleri, CORINE,

AÖ/AK değișimi,

Peyzaj değişimi, Ordu ili

\begin{abstract}
Özet: Ordu ilinde yürütülen bu çalışmada, 1990-2018 arasındaki dönemde meydana gelen arazi örtüsü/alan kullanımı değișimi CORINE arazi örtüsü veri tabanı kullanılarak incelenmiștir. Yapılan değerlendirmeler sonucunda 1990-2018 yılları arasında toplam 87.804 hektarlık alanda çeşitli değişimler meydana geldiği tespit edilmiştir. Ortaya çıkan en büyük değişim, orman ve yarı-doğal alanların, tarımsal alanlara dönüștürülmesi olup; toplam değișimin yaklașık \%77'sini olușturmaktadır. Bu değişim sonucunda orman ve yarı-doğal alanların miktarında yaklaşık \%19 oranında azalma görülmüștür. Süreç içerisinde kent dokusunu da içine alan yapay alan sınıfının büyüklüğünün $\% 92$ oranında artarak yaklaşık iki kat arttığı belirlenmiștir. Yapay alanlardaki artışın temel nedeni il ve bazı ilçelerde yaşanan hızlı kentleșme hareketleri, ormanlık alanlardaki azalıșın temel nedeni ise bu alanların il halkının temel geçim kaynağı olan fındık alanlarına dönüşümü olarak yorumlanmıştır.
\end{abstract}

\section{Evaluation of Land Cover/Land Use Change in Ordu Province (1990-2018) Using CORINE Data}

\section{Keywords}

Landscape metrics, CORINE,

LC/LU change,

Landscape change,

Ordu province

\begin{abstract}
In this study in Ordu province, the land cover / land use change that occurred between 1990-2018 was analyzed using the CORINE land cover database. As a result of the evaluations, it was determined that various changes occurred in a total area of 87.804 hectares between 1990-2018. The biggest change that has occurred is the transformation of forests and semi-natural areas into agricultural lands; it constitutes approximately $77 \%$ of the total change. As a result of this change, the amount of forests and semi-natural areas decreased by about $19 \%$. It has been determined that the size of the artificial area class, which also includes the urban fabric, has increased by $92 \%$ and almost doubled. The main reason for the increase in artificial areas was the rapid urbanization movements in the provinces and some districts, and the main reason for the decrease in forest areas was interpreted as the transformation of these areas into hazelnut areas, which are the main livelihoods of the people of the province.
\end{abstract}

\section{Giriş}

İnsanoğlu doğayı sürekli olarak değiștirmiş, yeniden șekillendirmiştir. Günümüzde bu değişim süreçleri oldukça hızlı ve çoğu zaman ekosistemleri olumsuz etkileyecek, hatta yok edecek ivmelerle devam etmektedir. Çağımızın en önemli sorunlarından biri olan insan kaynaklı arazi değişiminin hızlanması ve tüketim konusunda bitmeyen yeni ihtiyaçların ortaya çıkması, arazi üzerinde meydana gelen bozulmaların temelini oluşturmaktadır [1]. Arazinin bozulmadan gelecek nesillere aktarılması, hiç şüphesiz doğru ve planlı kullanılmasına bağlıdır. $\mathrm{Bu}$ açıdan ele alındığında arazi örtüsü değişimlerinin tespit edilerek eğilimlerinin belirlenmesi oldukça büyük önem arz etmektedir [2].

Arazi örtüsü/alan kullanımı ve bunların zaman içindeki değișiklikleri hakkındaki bilgiler, küresel sistem, çevre ve insanlar üzerindeki etkiyi

*ilgili yazar: mesutguzel@odu.edu.tr 
değerlendirmek [3], politika kararları, düzenlemeler, doğal kaynakların planlaması ve yönetimi (örneğin geliştirme, koruma), çevresel değişkenlerin modellemesi ve habitatların dağılımını anlamak ve arazi kullanımı faaliyetleri arasında bağlantı kurmak açısından oldukça önemlidir [4-7]. Bu veriler, peyzaj temelli ölçümler oluşturmak, peyzaj koşullarını değerlendirmek ve belirli bir zaman aralığı boyunca durum ve eğilimleri izlemek için sıklıkla kullanılır [8, 9].

Uzaktan algllama ve dijital görüntü işleme; çeşitli mekânsal, zamansal ve tematik ölçeklerde arazi örtüsünün gözlemlenmesini, tanımlanmasını, haritalandırılmasını, değerlendirilmesini ve izlenmesini sağlamaktadır [5]. Arazi örtüsü türlerinin tanımlanması, diğer tematik haritaların oluşturulması için temel bilgileri sağlamakta ve izleme faaliyetleri için bir temel oluşturmaktadır. Arazi kullanımı ve arazi örtüsü sınıflandırmasının amacı, temsil edilen fiziksel arazi türünü ve kullanımını (yerleşim alanı, endüstriyel alan, vb.) tanımlayan etiketleri otomatik olarak sağlamaktır [10].

Arazi örtüsünde zaman içerisinde meydana gelen değişimlerin belirlenmesinde peyzajın dördüncü boyutu olarak kabul edilen zamansal verilere ihtiyaç vardır. Bu nedenle CORINE verileri ve aynı alana ait farklı zamanlarda alınmış uydu görüntüleri oldukça önemlidir [2]. Bu çalışma kapsamında; kaynakların rasyonel kullanımı ve çevreye duyarlı alan kullanımı kararlarına altlık oluşturmak üzere, Ordu ilinde 19902018 yılları arasında gerçekleşen arazi örtüsü değişimlerinin CORINE verileri kullanılarak belirlenmesi ve bu değişimlerin bazı peyzaj metrikleri aracılığıyla değerlendirilmesi amaçlanmıştır.

\section{Materyal ve Metot}

Araştırma alanı olarak Karadeniz Bölgesi'nde bulunan Ordu ili seçilmiştir. Ordu ili; $41^{\circ} 08^{\prime}$ ve $40^{\circ} 20^{\prime}$ kuzey enlemleri ile $36^{\circ} 40^{\prime}$ ve $38^{\circ} 06^{\prime}$ doğu boylamları arasında yer almaktadır. Doğuda Giresun ili, batıda
Samsun ili, güneyde Sivas ve Tokat illeri, kuzeyde ise Karadeniz ile komşu olan Ordu ilinin yüzölçümü yaklaşık $5.952 \mathrm{~km}^{2}$ 'dir (Şekil 1).

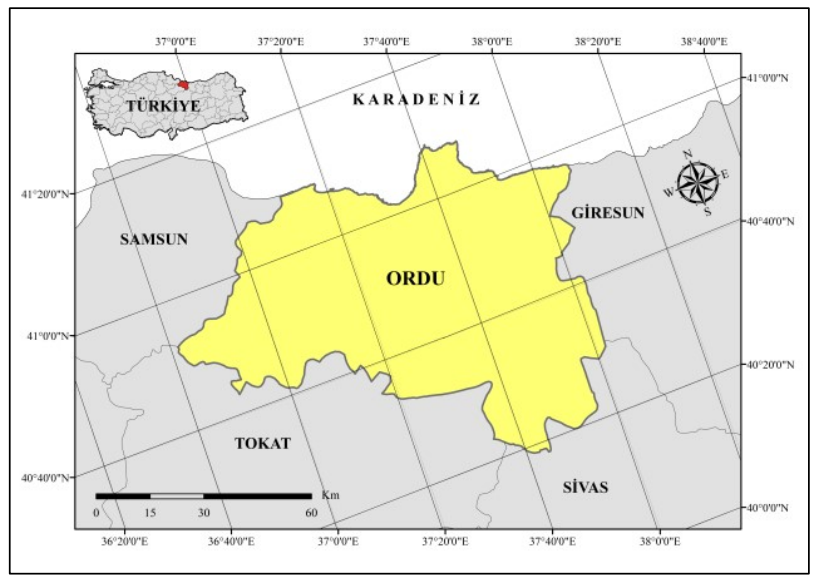

Şekil 1. Ordu ilinin konumu

2019 yılı itibariyle toplam nüfusu 754.198 olan Ordu ilinde halkın geçim kaynağı büyük ölçüde meyveciliğe ve kısmen ticarete dayanır [11]. Bunlar dışında ilde balıkçılık, arıcılık, hayvancılık ve ormancılık da önemli bir yer tutar. İldeki bitkisel üretim içerisinde en önemli unsur, Türkiye üretiminin de \%25'ini oluşturan findıktır [12].

Ordu ili arazi örtüsü/alan kullanımı değişimlerinin belirlenmesinde, Avrupa Çevre Ajansı tarafından oluşturulan sınıflandırma sistemini esas alan CORINE arazi örtüsünün 1990, 2000, 2006, 2012 ve 2018 yıllarında yayımlanan versiyonlarından yararlanılmıştır. ETRS_1989_LAEA koordinat sisteminde elde edilen veriler ArcMap 10.4 yazılımı ortamında işlenerek, arazi örtüsünde meydana gelen değişimler belirlenmiştir. ArcMap yazılımına eklenebilen Patch Analyst modülü aracılığıyla peyzaj metrikleri hesaplanmıştır. Arazi örtüsü/alan kullanımındaki değişimleri değerlendirmek üzere hesaplanan peyzaj metrikleri Tablo 1'de verilmiştir [13-18].

Tablo 1. Çalıșmada kullanılan peyzaj metrikleri

\begin{tabular}{cllll}
\hline Kısaltma & Metrik adı (İng.) & Metrik adı (Tür.) & \multicolumn{1}{c}{ Tanım } & Metrik türü \\
\hline \multirow{2}{*}{ TLA } & $\begin{array}{l}\text { Total Landscape } \\
\text { Area }\end{array}$ & $\begin{array}{l}\text { Toplam Peyzaj } \\
\text { Alanı }\end{array}$ & $\begin{array}{l}\text { Farklı alan kullanım sınıflarından oluşan peyzajın } \\
\text { toplam alanının hektar olarak karşılığıdır. }\end{array}$ & Alan Metriği \\
\hline CA & Class Area & Sınıf Alanı & $\begin{array}{l}\text { Alan kullanım sınıflarından her birine ait } \\
\text { lekelerin toplam alanıdır. }\end{array}$ & Leke Metriği \\
\hline \multirow{2}{*}{ NumP } & $\begin{array}{l}\text { Number of } \\
\text { Patches }\end{array}$ & Leke Sayısı & $\begin{array}{l}\text { Bir alan kullanım sinıfına ait olan lekelerin } \\
\text { toplam sayısıdır. }\end{array}$ & \\
\hline \multirow{2}{*}{ TE } & Mean Patch Size & $\begin{array}{l}\text { Ortalama Leke } \\
\text { Büyüklüğü }\end{array}$ & $\begin{array}{l}\text { Bir alan kullanım sinıfının toplam alanının leke } \\
\text { sayısına bölünmesiyle elde edilen değerdir. }\end{array}$ & Kenar Metriği \\
\hline \multirow{2}{*}{ ED } & Edge Density & Kenar Yoğunluğu & $\begin{array}{l}\text { Toplam kenar uzunluğunun toplam peyzaj } \\
\text { alanına bölünmesiyle elde edilen değerdir. }\end{array}$ & \\
\hline
\end{tabular}


Peyzaj metrikleri; lekelerin, leke sınıflarının ya da tüm peyzaj mozaiğinin mekânsal yapısını ölçmede ve tanımlamada kullanılan araçlardır. $\mathrm{Bu}$ araçlar, planlamacılara peyzajların yapısı ve bileşenleri hakkında önemli bilgiler verirler [19]. Parçalanma gibi dönüşüm süreçleri ile büyük lekeler daha küçük parçalara ayrılabilmektedir [20]. Bu sebeple NumP (Leke sayısı) parçalanmaya işaret etmektedir. İki farklı zaman dilimi arasında leke sayısının artmış olması parçalanma süreçlerinin yaşandığını göstermektedir [19]. Tersi şekilde MPS (Ortalama leke büyüklüğü) değerinde meydana gelen azalmalar parçalanmanın göstergesidir. TE (Toplam kenar) uzunluğu değerinin geçmişteki duruma göre artmış olması o sınıfın ya da tüm peyzajın parçalanmaya daha yatkın bir duruma geldiğinin işaretini vermektedir. ED (Kenar yoğunluğu) değerinin artması ise parçalanmanın ileri düzeyde gerçekleştiğini göstermektedir [14].

Çalışmada, arazi örtülerini üç farklı düzeyde sinıflandıran CORINE sisteminin birinci düzeyi esas alınmıştır. Bu düzeyde araziler 5 ana sınıfa ayrılmıştır [21]. Bunlar; yapay alanlar, tarımsal alanlar, orman ve yarı-doğal alanlar, sulak alanlar ile su yüzeyleridir (Tablo 2). CORINE arazi sinıflandırmasına göre Ordu ilinde sulak alan sınıfında herhangi bir alan bulunmamaktadır. Bu sebeple çalışmada sulak alanlar sınıfına yer verilmemiş, yalnızca 4 sınıf üzerinden değerlendirme yapılmıştır (Şekil 2).

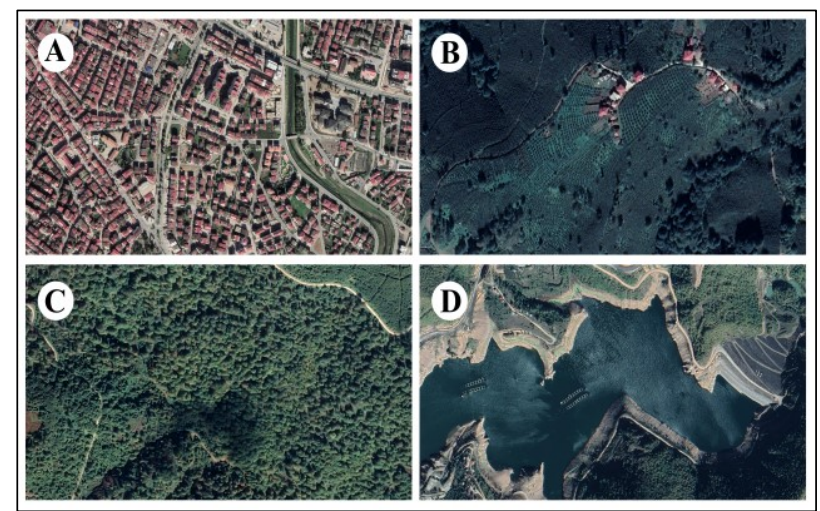

Şekil 2. Ordu ilindeki arazi örtüsü/arazi kullanımı örnekleri (A: Yapay alanlar, B: Tarımsal alanlar, C: Ormanlar ve yarıdoğal alanlar, D: Su yüzeyleri)

\section{Bulgular}

Araştırmada CORINE sistemine göre yapılan arazi sınıflandırmasının birinci basamağındaki beş sınıftan, Ordu ilinde örneği bulunan dört sınıfta (yapay alanlar, tarımsal alanlar, su yüzeyleri, ormanlar ve yarı-doğal alanlar) değişim meydana geldiği belirlenmiștir. Ordu ili arazi örtüsü/alan kullanımında 1990-2018 yılları arasında meydana gelen bu değişim Şekil 3'te verilmiştir. 28 yıllık süreç boyunca en fazla değişim, \%92 oranında bir artış göstererek, neredeyse 2 katı alana ulaşan yapay alanlarda meydana gelmiştir. Yine 2018 yılına gelindiğinde tarımsal alanlar 1990 yılındaki alanına göre \%18, su yüzeyleri ise yaklaşık \%13 oranında artış göstermiştir. Ormanlar ve yarıdoğal alanlarda ise yaklaşık \%19 oranında bir azalma meydana gelmiştir (Tablo 3).

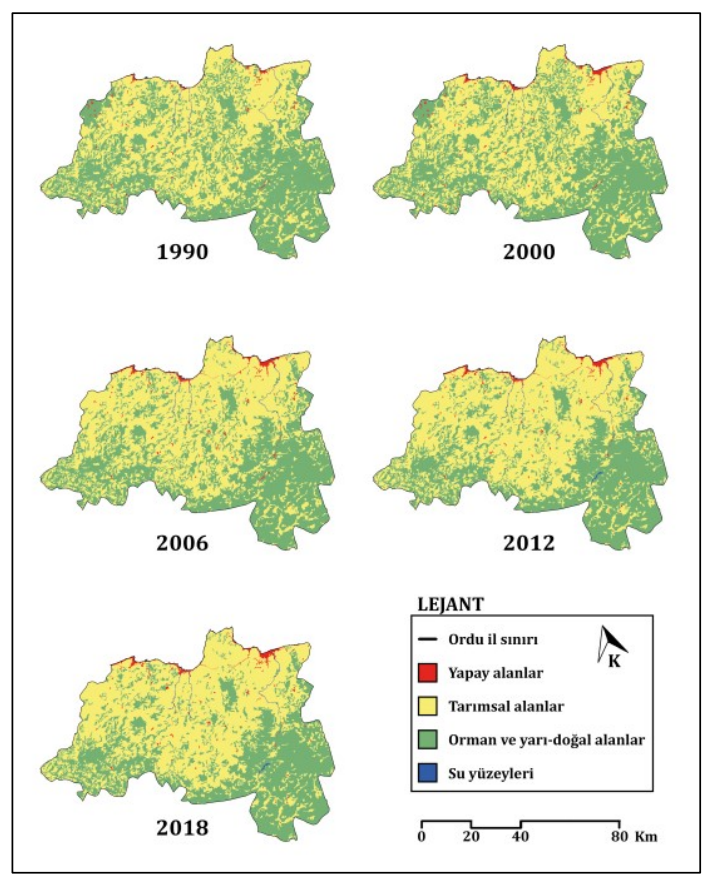

Şekil 3. Ordu ili arazi örtüsü/alan kullanımında zaman içerisinde meydana gelen değişim (1990-2018)

Ordu ilindeki yapay alan sınıfının büyüklüğü 19902000 arasındaki 10 yıllık dönemde \%47, 2000-2006 arasında ise \%21.5 oranında artarak 4165 hektardan 7440 hektara çıkmıştır (Tablo 3.)

Tablo 2. CORINE birinci düzey arazi sınıfları ve kapsamları

\begin{tabular}{cc}
\hline CORINE Arazi Sınıfı & Arazi Sınıfının Kapsamı \\
\hline 1.Yapay alanlar & $\begin{array}{c}\text { Sürekli ve süreksiz kent yapısı; endüstri ve ticaret birimleri; limanlar, havaalanları, } \\
\text { maden ocağı, boșaltım ve inșaat alanları; kentsel yeșil alanlar }\end{array}$ \\
\hline 2.Tarımsal alanlar & $\begin{array}{c}\text { Ekilebilir alanlar; pirinç tarlaları; üzüm bağları; meyve bahçeleri; zeytinlikler; } \\
\text { meralar; karıșılk tarımsal alanlar }\end{array}$ \\
\hline 3.0rman ve yarı-doğal alanlar & $\begin{array}{c}\text { Geniş yaprakları ormanlar; iğne yapraklı ormanlar; karıșık ormanlar; çayırlıklar, } \\
\text { fundalıklar; sahiller; kumullar; yanmış alanlar; kalıcı karlı ve buzul alanları }\end{array}$ \\
\hline 4.Sulak alanlar & Bataklıklar; turbalıklar; tuzlalar; gelgit sonucu oluşan düzlükler \\
\hline 5.Su yüzeyleri & Su yolları; su kütleleri; kıyı lagünleri; nehir ağızları; deltalar, denizler, okyanuslar \\
\hline
\end{tabular}


Tablo 3. Arazi örtüsü/alan kullanımı sınıflarının yıllara göre değișim yüzdeleri

\begin{tabular}{|c|c|c|c|c|c|c|c|c|c|c|}
\hline \multirow{2}{*}{$\begin{array}{c}\text { Arazi örtüsü/alan } \\
\text { kullanımı }\end{array}$} & \multicolumn{5}{|c|}{ Alan (ha) } & \multicolumn{5}{|c|}{$\Delta \%$} \\
\hline & 1990 & 2000 & 2006 & 2012 & 2018 & $\begin{array}{l}1990- \\
2000\end{array}$ & $\begin{array}{l}2000- \\
2006\end{array}$ & $\begin{array}{l}2006- \\
2012\end{array}$ & $\begin{array}{l}2012- \\
2018\end{array}$ & $\begin{array}{l}1990- \\
2018\end{array}$ \\
\hline Yapay alanlar & 4165 & 6123 & 7440 & 7547 & 7998 & 47.01 & 21.5 & 1.45 & 5.97 & 92.03 \\
\hline Tarımsal alanlar & 284564 & 282562 & 320699 & 335978 & 335897 & -0.7 & 13.5 & 4.76 & -0.02 & 18.04 \\
\hline $\begin{array}{c}\text { Orman ve yarı-doğal } \\
\text { alanlar }\end{array}$ & 296725 & 296768 & 257286 & 241633 & 241290 & 0.01 & -13.3 & -6.08 & -0.14 & -18.68 \\
\hline Su yüzeyleri & 2139 & 2140 & 2168 & 2435 & 2408 & 0.04 & 1.31 & 12.32 & -1.13 & 12.58 \\
\hline
\end{tabular}

Çalışmada incelenen 28 yıllık dönemde artış oranı değişken olsa da, yapay alanların miktarının devamlı olarak artma eğiliminde olduğu görülmektedir. 2018 yılı itibariyle yapay alanların büyüklüğü 7998 hektara ulaşmıştır. Tarımsal alanların miktarındaki en büyük artış 2000-2006 yılları arasında gerçekleşmiştir. Bu dönemi takip eden 6 yıllık dönemde ise artış oranı \%4.76'dır. $1990-2000$ ve 2012-2018 yılları arasındaki dönemlerde tarımsal alanların miktarında \%1'in altında bir azalma görülmüştür. 2000 yılına kadar orman ve yarı-doğal alanların miktarında önemli bir değişim olmamasına rağmen 2000-2006 arasında \%13.3, 2006-2012 arasında yaklaşık \%6.1'lik bir azalma meydana gelmiştir. 1990-2018 yılları arasında toplamda 55435 hektar büyüklüğünde orman ve yarıdoğal nitelikteki alanın diğer arazi örtüsü/alan kullanımı sınıflarına dönüştüğü görülmektedir. Su yüzeylerindeki alansal artış \%12.32 oranı ile en fazla 2006-2012 yılları arasında gerçekleşmiştir. Bu da 267 hektar büyüklügünde yeni bir su yüzeyinin kazanıldığını göstermektedir (Tablo 3).

Ordu'da 1990 ve 2018 arasındaki dönemde toplam 87804 hektarlık alanda çeşitli değişimler meydana gelmiştir (Şekil 4). Bu değişimler içerisinde en büyüğü, toplam değişimin yaklaşık \%77'sini oluşturan orman ve yarı-doğal alanların tarımsal alanlara dönüștürülmesidir (Tablo 4). 28 yıllık süreçte toplam 4851.46 hektar tarımsal alan ve 423.12 hektar orman ve yarı-doğal alan, yapay alanlara dönüştürülmüştür.

Farklı arazi örtüsü/alan kullanımı sınıflarında meydana gelen değişimi anlamak ve tanımlamak amacıyla hesaplanan metrik değerleri Tablo 5'te verilmiştir. Parçalanmanın en önemli göstergelerinden olan leke sayısı (NumP) ve ortalama leke büyüklüguünde (MPS) meydana gelen değişimler incelendiğinde, yapay alan sınıfındaki leke sayısının zaman içerisinde sürekli arttığı görülmektedir. Orman ve yarı-doğal alan sınıfındaki lekelerin sayısı 19902012 yılları arasında azalma eğilimindeyken, 20122018 arasında \%1 oranında artmıştır.

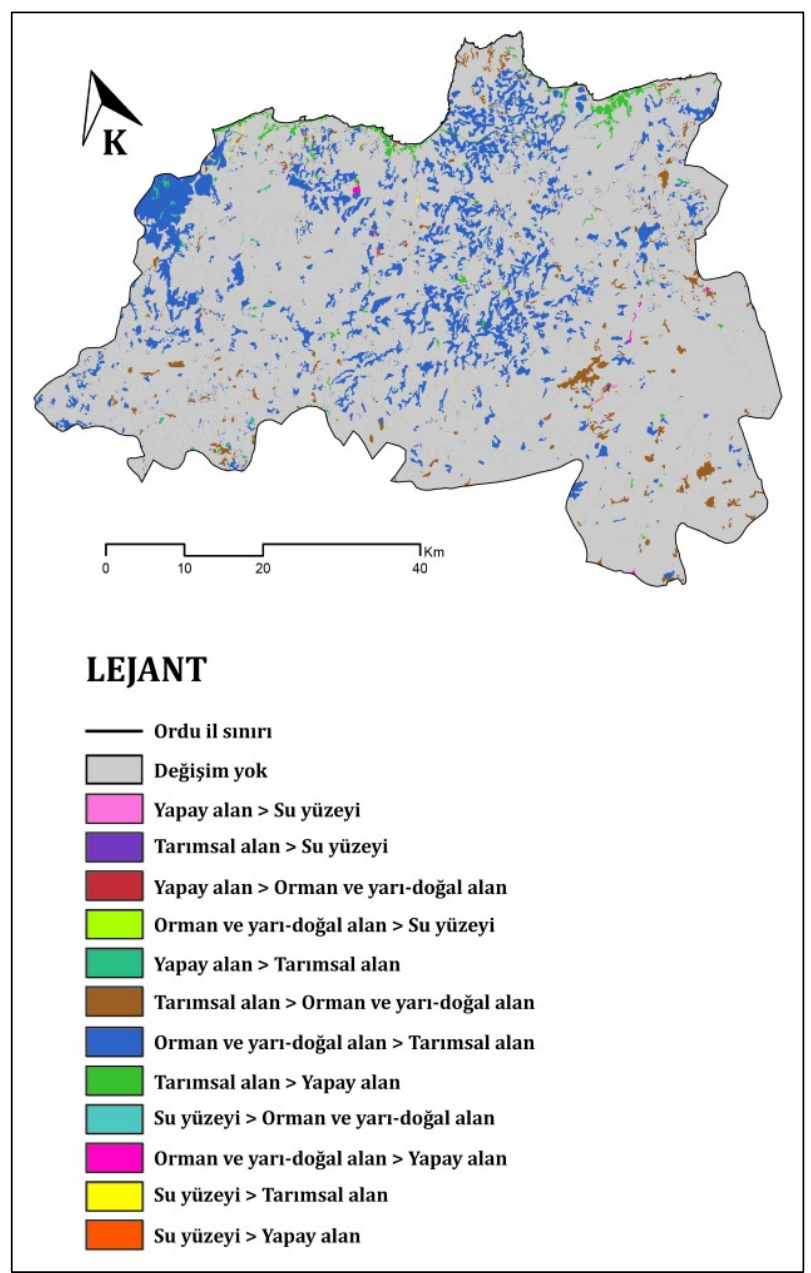

Şekil 4. Ordu ilinde 1990-2018 yılları arasında gerçekleşen alan kullanımı değişimi

Tablo 4. Arazi örtüsü/alan kullanımındaki değişimlerin alansal karşılığı

\begin{tabular}{ccc}
\hline Değișim türü & Alan (ha) & Yüzde (\%) \\
\hline Değişim yok & 499789.07 & - \\
\hline Orman ve yarı-doğal alan $\rightarrow$ Tarımsal alan & 67592.03 & 76.98 \\
\hline Tarımsal alan $\rightarrow$ Orman ve yarı-doğal alan & 12593.63 & 14.34 \\
\hline Tarımsal alan $\rightarrow$ Yapay alan & 4851.46 & 5.53 \\
\hline Yapay alan $\rightarrow$ Tarımsal alan & 1304.23 & 1.49 \\
\hline Diğer değişimler & 1462.75 & 1.66 \\
\hline
\end{tabular}


Tablo 5. Farklı arazi örtüsü/alan kullanımı sınıflarına ait peyzaj metrik değerleri

\begin{tabular}{|c|c|c|c|c|c|c|c|c|c|c|}
\hline \multirow{2}{*}{$\begin{array}{c}\text { Peyzaj } \\
\text { metriği* }\end{array}$} & \multicolumn{9}{|c|}{ Yapay alanlar } & \multicolumn{4}{c|}{$\mathbf{\Delta \%}$} \\
\cline { 2 - 12 } & $\mathbf{1 9 9 0}$ & $\mathbf{2 0 0 0}$ & $\mathbf{2 0 0 6}$ & $\mathbf{2 0 1 2}$ & $\mathbf{2 0 1 8}$ & $\begin{array}{c}\mathbf{1 9 9 0 -} \\
\mathbf{2 0 0 0}\end{array}$ & $\begin{array}{c}\mathbf{2 0 0 0}- \\
\mathbf{2 0 0 6}\end{array}$ & $\begin{array}{c}\mathbf{2 0 0 6} \\
\mathbf{2 0 1 2}\end{array}$ & $\begin{array}{c}\mathbf{2 0 1 2 -} \\
\mathbf{2 0 1 8}\end{array}$ & $\begin{array}{c}\mathbf{1 9 9 0} \\
\mathbf{2 0 1 8}\end{array}$ \\
\hline TLA & 587593 & 587593 & 587593 & 587593 & 587593 & - & - & - & - & - \\
\hline CA & 4165.09 & 6122.88 & 7439.53 & 7547.24 & 7997.61 & 47.00 & 21.50 & 1.45 & 5.97 & $\mathbf{9 2 . 0 2}$ \\
\hline NumP & 77 & 89 & 96 & 101 & 107 & 15.58 & 7.87 & 5.21 & 5.94 & $\mathbf{3 8 . 9 6}$ \\
\hline MPS & 54.0921 & 68.7965 & 77.4951 & 74.7252 & 74.744 & 27.18 & 12.64 & -3.57 & 0.03 & $\mathbf{3 8 . 1 8}$ \\
\hline TE & 351515 & 445172 & 602599 & 629456 & 662015 & 26.64 & 35.36 & 4.46 & 5.17 & $\mathbf{8 8 . 3 3}$ \\
\hline ED & 0.59822 & 0.75762 & 1.02554 & 1.07125 & 1.12666 & 26.64 & 35.36 & 4.46 & 5.17 & $\mathbf{8 8 . 3 3}$ \\
\hline
\end{tabular}

\begin{tabular}{|c|c|c|c|c|c|c|c|c|c|c|}
\hline \multirow{2}{*}{$\begin{array}{c}\text { Peyzaj } \\
\text { metriği }\end{array}$} & \multicolumn{5}{|c|}{ Ormanlar ve yarı-doğal alanlar } & \multicolumn{5}{|c|}{$\Delta \%$} \\
\hline & 1990 & 2000 & 2006 & 2012 & 2018 & $\begin{array}{l}1990- \\
2000\end{array}$ & $\begin{array}{c}2000- \\
2006\end{array}$ & $\begin{array}{c}2006- \\
2012\end{array}$ & $\begin{array}{l}2012- \\
2018\end{array}$ & $\begin{array}{l}1990- \\
2018\end{array}$ \\
\hline TLA & 587593 & 587593 & 587593 & 587593 & 587593 & - & - & - & - & - \\
\hline CA & 296725 & 296768 & 257286 & 241633 & 241290 & 0.01 & -13.30 & -6.08 & -0.14 & -18.68 \\
\hline NumP & 1376 & 1357 & 1164 & 1026 & 1036 & -1.38 & -14.22 & -11.86 & 0.97 & -24.71 \\
\hline MPS & 215.643 & 218.694 & 221.036 & 235.51 & 232.906 & 1.41 & 1.07 & 6.55 & -1.11 & 8.01 \\
\hline TE & 137133 & 135382 & 119578 & 109206 & 109633 & -1.28 & -11.67 & -8.67 & 0.39 & -20.05 \\
\hline ED & 23.3381 & 23.0401 & 20.3504 & 18.5853 & 18.6579 & -1.28 & -11.67 & -8.67 & 0.39 & -20.05 \\
\hline
\end{tabular}

\begin{tabular}{|c|c|c|c|c|c|c|c|c|c|c|}
\hline \multirow{2}{*}{$\begin{array}{l}\text { Peyzaj } \\
\text { metriği }\end{array}$} & \multicolumn{5}{|c|}{ Tarımsal alanlar } & \multicolumn{5}{|c|}{$\Delta \%$} \\
\hline & 1990 & 2000 & 2006 & 2012 & 2018 & $\begin{array}{l}1990- \\
2000\end{array}$ & $\begin{array}{l}2000- \\
2006\end{array}$ & $\begin{array}{l}2006- \\
2012 \\
\end{array}$ & $\begin{array}{l}2012- \\
2018\end{array}$ & $\begin{array}{l}1990- \\
2018\end{array}$ \\
\hline TLA & 587593 & 587593 & 587593 & 587593 & 587593 & - & - & - & - & - \\
\hline CA & 284564 & 282562 & 320699 & 335978 & 335897 & -0.70 & 13.50 & 4.76 & -0.02 & 18.04 \\
\hline NumP & 968 & 972 & 1227 & 1073 & 1070 & 0.41 & 26.23 & -12.55 & -0.28 & 10.54 \\
\hline MPS & 293.971 & 290.701 & 261.369 & 313.12 & 313.922 & -1.11 & -10.09 & 19.80 & 0.26 & 6.79 \\
\hline TE & 115278 & 114971 & 141556 & 139068 & 139250 & -0.27 & 23.12 & -1.76 & 0.13 & 20.79 \\
\hline ED & 19.6187 & 19.5664 & 24.0908 & 23.6674 & 23.6984 & -0.27 & 23.12 & -1.76 & 0.13 & 20.79 \\
\hline
\end{tabular}

\begin{tabular}{|c|c|c|c|c|c|c|c|c|c|c|}
\hline \multirow{2}{*}{$\begin{array}{l}\text { Peyzaj } \\
\text { metriği }\end{array}$} & \multicolumn{5}{|c|}{ Su yüzeyleri } & \multicolumn{5}{|c|}{$\Delta \%$} \\
\hline & 1990 & 2000 & 2006 & 2012 & 2018 & $\begin{array}{l}1990- \\
2000\end{array}$ & $\begin{array}{l}2000- \\
2006\end{array}$ & $\begin{array}{l}2006- \\
2012\end{array}$ & $\begin{array}{c}2012- \\
2018\end{array}$ & $\begin{array}{l}1990- \\
2018\end{array}$ \\
\hline TLA & 587593 & 587593 & 587593 & 587593 & 587593 & - & - & - & - & - \\
\hline CA & 2138.89 & 2139.82 & 2167.91 & 2435.1 & 2407.65 & 0.04 & 1.31 & 12.32 & -1.13 & 12.57 \\
\hline NumP & 7 & 7 & 5 & 8 & 9 & 0.00 & -28.57 & 60.00 & 12.50 & 28.57 \\
\hline MPS & 305.555 & 305.689 & 433.583 & 304.387 & 267.516 & 0.04 & 41.84 & -29.80 & -12.11 & -12.45 \\
\hline TE & 387528 & 384711 & 380004 & 400676 & 394035 & -0.73 & -1.22 & 5.44 & -1.66 & 1.68 \\
\hline ED & 0.65951 & 0.65472 & 0.64671 & 0.68189 & 0.67059 & -0.73 & -1.22 & 5.44 & -1.66 & 1.68 \\
\hline
\end{tabular}

* TLA: Toplam peyzaj alanı, CA: Sınıf alanı, NumP: Leke sayısı, MPS: Ortalama leke büyüklüğü, TE: Toplam kenar, ED: Kenar yoğunluğu.

Tarımsal alan sınıfında leke sayısı 2000-2006 döneminde \%26 artmış, 2006-2012 arasında ise \%13 oranında azalmıştır. Su yüzeyi sınıfında leke sayısı 2000 yılına kadar 7 iken önce 5'e düşmüş sonrasında ise 9'a yükselmiştir. Ortalama leke büyüklügü̈; yapay alan, orman ve yarı-doğal alan ile tarımsal alan sınıflarında 1990-2018 arasında artış göstermiştir. Su yüzeyi sınıfında ise ortalama leke büyüklüğü \%12.5 oranında azalmıştır. 1990-2018 yılları arasında orman ve yarı-doğal alan sınıfında toplam kenar uzunluğu ve kenar yoğunluğu \%20 oranında azalmıştır. Yapay alan sınıfında toplam kenar uzunluğu 1990-2000 yılları arasında yaklaşık \%27, 2000-2006 yılları arasında \%35 oranında artış göstermiştir. Yapay alan sınıfında 28 yılda meydana gelen toplam değişime bakıldığında, toplam kenar uzunluğu ve kenar yoğunluğunun \%88 oranında arttığı görülmektedir. Tarımsal alan sınıfında kenar uzunluğu ve kenar yoğunluğu bakımından en fazla değişim \%23 oranı ile 2000 ve 2006 yılları arasında yaşanmıştır. Tarımsal alan sınıfındaki toplam kenar uzunluğu 28 yıllık süreçte yaklaşık \%21 oranında artmıştır. Su yüzeylerinde 2006-2012 yılları arasında kenar yoğunluğu ve toplam kenar uzunluğu \%5 artış göstermiştir (Tablo 5).

\section{Tartışma ve Sonuç}

Çalışmanın zamansal sınırını oluşturan 1990-2018 yılları arasındaki 28 yıllık süreçte en büyük değişim \%92 oranında artış göstererek neredeyse 2 katına ulaşan yapay alanlarda meydana gelmiştir. Daha önce farklı şehirlerde yapılan çalışmalarda da benzer sonuçlara ulaşılmıştır $[18,22,23]$. Bu durumun oluşmasında en büyük etken olarak, Ordu ilinin 2013 yılında büyükşehir statüsü kazanması görülmektedir. Özellikle kent merkezinin içinde yer aldığı Altınordu ilçesinde yaşanan kentleşme hareketleri, bu süreçten 
sonra hız kazanmıştır. İlçedeki yerleşim alanları güney ve doğu yönlerinde gelişim göstermektedir. Bu gelişimin temel nedeni, doğu yönünde Üniversite ve havaalanının yer alması iken, güney yönünde TOKİ tarafından açılan yerleşim alanları ve çok hızlı bir ivme ile toplu konut yerleşmelerinin ortaya çıtığı mahallelerdir. Altınordu ilçesinden sonra yapılaşmanın en yoğun görüldüğü ilçeler Ünye ve Fatsa ilçeleridir. Yapılaşmaya ek olarak Ordu ilinde havaalanı, çevreyolu gibi yatırımların son yıllarda artması yine yapay alan sınıfının artış gösterme sebeplerindendir. Atabeyoğlu'na (2014) göre; kentte üniversitenin yer alması, havaalanının inșa edilmesi, kente büyükşehir statüsü verilmesi gibi olgular kentin gelişimini hızlandıracak ve bunlara paralel olarak nüfusun artmasını sağlayacaktır [24]. Bugün gelinen noktada bu tespitin son derece isabetli olduğu görülmektedir. Ordu ilinde özellikle son on yılda nüfusun artışına paralel olarak kentleşme hızlı bir şekilde gelişim ve yayılım göstermiştir.

Özellikle 2000-2006 yılları arasındaki dönemde tarımsal alan sınıfında \%13.5 oranında artış olmuştur. Aynı dönemde orman ve yarı-doğal alan sınıfında da benzer oranda bir azalma gerçekleşmiştir. Ordu halkının, kendisi için önemli bir geçim kaynağı olan fındık alanlarını artırma eğiliminde olduğu ve değișimin temel sebebinin, ormanlık alanların findık bahçelerine dönüştürülmesi olduğu görülmektedir. Bu dönüşüm sonucunda, toplam 67592 hektar büyüklüğünde orman ve yarı-doğal nitelikteki alan tarımsal üretim alanlarına dönüşmüştür. Bu değişim toplam değişimin yaklaşık \%77'sini oluşturmaktadır. $\mathrm{Su}$ yüzeyi sınıfında 2006-2012 yılları arasında meydana gelen \%12'lik artışın en önemli sebebi ise 1996 yılında yapımına başlanan Mesudiye Topçam Barajı ve göletidir.

1990-2018 yılları arasındaki dönemde yeni yerleşimler oluşturulması, mevcut yerleşimlerin parçalı bir gelişim göstermesi, Ünye ilçesinde bentonit kili yataklarının oluşturulması, Fatsa ilçesinde altın madeninin inşa edilmesi gibi nedenlerle yapay alanların sınıf alanında artış gerçekleşmiştir. Bu durum aynı zamanda leke sayısında ve ortalama leke büyüklügünde de artışa sebep olmuştur. Orman ve yarı-doğal alan sınıfında leke sayısı yaklaşık \%25 azalmış, ortalama leke büyüklüğü \%8 oranında artmıştır. Bu durumun oluşmasında daha önceleri parçalı bir şekilde bulunan ormanlık alanların tarım alanlarına dönüştürülmesinin etkili olduğu düşünülmektedir. Sonuç olarak; toplam kenar uzunluğu, kenar yoğunluğu ve leke sayısının azalması, buna karşılık ortalama leke büyüklüğünün artması bahsi geçen arazi örtüsü/alan kullanımı sınıfının daha dengeli ve bütün bir yapıya dönüștügünü göstermektedir.

Alan kullanımlarında ve peyzajlarda ortaya çıkan değişimlerin, doğal ve sosyal süreçlerin analizi, çevre odaklı projeler için önemli girdiler içermekte ve dolayısıyla peyzaj yönetiminin önemli bir bileşenini temsil etmekte; peyzaj değerlendirmesi ve peyzaj değişikliklerinin tanımlanması için bir araç olarak karşımıza çıkmaktadır. Elde edilen veriler ekolojiekonomi ekseninde değerlendirilerek plan kararları oluşturulmalıdır. Yapay alanların ormanlar ve tarım alanlarına baskısı dikkate alınmalı, yine tarım alanları açılması nedeni ile ortaya çıkan orman kaybı önlenmelidir.

Yapılan bu çalışma ile Ordu iline ait beş farklı yılda oluşturulmuş CORINE haritaları kullanılarak arazi örtüsü/alan kullanımında meydana gelen değişimler ortaya konulmuştur. Bu çalışma, Ordu özelinde yapılan peyzaj değişimi çalışmalarının ilki olması sebebiyle önemlidir. Çalışmada CORINE sınıflandırmasının yalnızca birinci düzeyi kullanılarak il genelinde bir değerlendirme yapılmıştır. Gelecekte, özellikle merkez ilçe olan Altınordu'yu ve diğer ilçeleri kapsayacak şekilde yaplacak çalışmalar ile arazi örtüsünde meydana gelen değişimler daha detaylı biçimde tespit edilebilecektir. 1990 yılı öncesi uydu görüntüleri kullanılarak yapılacak daha detaylı bir sınıflandırmayla, çok daha eski tarihler ile bugünün kıyaslaması yapılabilir ve daha köklü değişimler ortaya konulabilir. Dolayısıyla bu çalışma, bundan sonra yapılacak daha detaylı ve/veya daha uzun süreçli çalıșmalar ve ilerleyen dönemlerde yapılacak izleme çalışmaları için bir altlık niteliği taşıyacaktır.

\section{Etik Beyanı}

Bu çalışmada, "Yükseköğretim Kurumları Bilimsel Araștırma ve Yayın Etiği Yönergesi" kapsamında uyulması gerekli tüm kurallara uyulduğunu, bahsi geçen yönergenin "Bilimsel Araştırma ve Yayın Etiğine Aykırı Eylemler" başlığı altında belirtilen eylemlerden hiçbirinin gerçekleştirilmediğini taahhüt ederiz.

\section{Kaynakça}

[1] Alevkayalı, Ç., Tağıl, Ș. 2018. Ortak Malların Trajedisi Üzerine Teoriler: Gediz Deltası'nda Arazi Kullanımı-Arazi Örtüsü Değișimi. Süleyman Demirel Üniversitesi Fen-Edebiyat Fakültesi Sosyal Bilimler Dergisi, 43, 120-142.

[2] Bayar, R., Karabacak, K. 2017. Ankara İli Arazi Örtüsü Değișimi (2000-2012). Coğrafi Bilimler Dergisi, 15(1), 59-76.

[3] Di Gregorio, A., Jansen, L. 2005. Land Cover Classification System (LCCS), Classification Concepts and User Manual. Food and Agriculture Organization (FAO) of the United Nations, Rome.

[4] Foody, G. M. 2002. Status of Land Cover Classification Accuracy Assessment. Remote Sensing of Environment, 80(1), 185-201.

[5] Rogan, J., Chen, D. 2004. Remote Sensing Technology For Mapping and Monitoring LandCover and Land-Use Change. Progress in Planning, 61(4), 301-325. 
[6] Lunetta, R. S., Knight, J. F., Ediriwickrema, J., Lyon, J. G., Worthy, L. D. 2006. Land-Cover Change Detection Using Multi-temporal MODIS NDVI Data. Remote Sensing of Environment, 105(2), 142-154.

[7] Gómez, C., White, J. C., Wulder, M. A. 2016. Optical Remotely Sensed Time Series Data for Land Cover Classification: A Review. ISPRS Journal of Photogrammetry and Remote Sensing, 116, 5572.

[8] Jones, K. B. 1997. An Ecological Assessment of The United States Mid-atlantic Region: A Landscape Atlas. US Environmental Protection Agency, Office of Research and Development.

[9] Phiri, D., Morgenroth, J. 2017. Developments in Landsat Land Cover Classification Methods: A Review. Remote Sensing, 9(9), 967.

[10] Helber, P., Bischke, B., Dengel, A., Borth, D. 2019. Eurosat: A Novel Dataset and Deep Learning Benchmark for Land Use and Land Cover Classification. IEEE Journal of Selected Topics in Applied Earth Observations and Remote Sensing, 12(7), 2217-2226.

[11] TÜİK, 2020. Türkiye İstatistik Kurumu. http://www.tuik.gov.tr (Erişim Tarihi: 17.09.2020).

[12] Anonim, 2018. Ordu Valiliği, Çevre ve Șehircilik İl Müdürlügü, Ordu İli 2017 Yılı Çevre Durum Raporu, Ordu.

[13] Atak, B. K. 2020. Kentsel Peyzaj Yapısındaki Değișimlerin Peyzaj Metrikleri ile Analizi: İzmir Örneği. Ege Üniversitesi Ziraat Fakültesi Dergisi, 57(1), 119-128.

[14] Doygun, N. 2017. Tarımsal Alan Kullanım Değișimlerinin Bazı Peyzaj Metrikleri ile İncelenmesi: Kahramanmaraş Örneği. Tarım ve Doğa Dergisi, 20(3), 270-275.
[15] Farina, A. 2000. Landscape Ecology in Action. Kluwer Academic Publishers, Boston.

[16] McGarigal, K., Marks, B. J. 1995. Fragstats: Spatial Pattern Analysis Program for Quantifying Landscape Structure. Oregon Forest Science Lab, Oregon.

[17] McGarigal, K., 2002. Landscape Pattern Metrics. El-Shaarawi, A. H., Piegorsch, W. W., ed. 2002. Encyclopedia of Environmetrics, England, 1135s.

[18] Oğuz, H., Zengin, M. 2011. Peyzaj Patern Metrikleri ve Landsat $5 \mathrm{Tm}$ Uydu Görüntüleri Kullanılarak Arazi Örtüsü/Arazi Kullanımı Değişimi Analizi (1984-2010): Kahramanmaraş Örneği. 1. Ulusal Akdeniz Orman ve Çevre Sempozyumu, 26-28 Ekim, Kahramanmaraş, 22 29.

[19] Leitão, A. B., Miller, J., Ahern, J., McGarigal, K. 2006. Measuring Landscapes: A Planner's Handbook, Island Press, England.

[20] Forman, R. T. T., Godron, M. 1986. Landscape Ecology. John Wiley and Sons, New York.

[21] EEA, 2020. CORINE Land Cover - European Environment Agency. https://www.eea.europa.eu/publications/COR0 -landcover (Erişim tarihi: 14.09.2020).

[22] Görmüș, S., Cengiz, S., Yılmaz, B. 2018. Peyzaj Metrikleri Kullanarak Peyzaj Dinamiklerinin Analizi: Malatya Kenti. TÜCAUM, 30, 3-6.

[23] Korgavuş, B. 2014. Rize Merkez İlçesi Kültürel Peyzaj Alanlarında Zamansal Değișimin Coğrafi Bilgi Sistemleri ile Belirlenmesi. Artvin Çoruh Üniversitesi Orman Fakültesi Dergisi, 15(2), 96113.

[24] Atabeyoğlu, Ö. 2014. Büyükșehir Olma Sürecinde Bir Kent: Ordu. Adnan Menderes Üniversitesi Sosyal Bilimler Enstitüsü Dergisi, 1, 160-177. 